\title{
DOPAMINE ELICITS FEEDING MOTOR PROGRAM IN LIMAX MAXIMUS
}

\author{
STEVEN J. WIELAND ${ }^{2}$ AND ALAN GELPERIN* \\ Department of Biology, Princeton University, Princeton, New Jersey 08544, and ${ }^{*}$ Department of Molecular Biophysics, \\ Bell Laboratories, Murray Hill, New Jersey 07974
}

Received December 20, 1982; Revised March 21, 1983; Accepted March 21, 1983

\begin{abstract}
A neural system within the cerebral and buccal ganglia of the terrestrial mollusc Limax maximus responds to lip chemostimulation by emitting a feeding motor program (FMP) in vivo and in vitro. We have analyzed chemically the cerebral and buccal ganglia of Limax for neurotransmitters involved in controlling expression of FMP. Dopamine was found in clusters of cells and in the neuropil of the cerebral ganglia at a concentration of $62 \mathrm{pmol} /$ ganglion; a large proportion of such dopamine-containing cells projected to the lips. The buccal ganglia contained several small dopaminergic cells and large amounts of dopamine in the neuropil; the measured concentration was 10 $\mathrm{pmol} /$ ganglion. Exogenous dopamine applied to the cerebral and buccal ganglia in vitro between $10^{-7} \mathrm{M}$ and $3 \times 10^{-6} \mathrm{M}$ excited an autoactive salivary duct motor neuron (FB) and inhibited an autoactive secretomotor neuron (BSN). Concentrations of dopamine between $3 \times 10^{-6} \mathrm{M}$ and $3 \times$ $10^{-5} \mathrm{M}$ triggered FMP output, with an increased probability of triggering at higher concentrations of dopamine. ADTN and SK\&F38393 were potent agonists in this system, whereas ergonovine was the only potent antagonist found; none of the neuroleptics tested was effective. Thus, the Limax system shows agonist responses similar to the vertebrate D1 receptors, but its antagonist-binding properties appear to have requirements quite different from vertebrate receptors.

The effects of exogenous serotonin differed from dopamine's effects; serotonin excited BSN and several buccal motor neurons, could not elicit synchronized motor program cycling, and was not efficiently blocked by ergonovine.

'These data suggest that dopamine is a good candidate as an endogenous triggering and sustaining transmitter for the Limax feeding motor program.
\end{abstract}

The neuronal system underlying feeding behavior in the terrestrial mollusc Limax maximus exhibits several forms of plasticity, including proprioceptive modulation (Reingold and Gelperin, 1980), inhibition by satiety (Gelperin, 1983), and associative conditioning (Sahley et al., $1981,1983)$. Of particular interest, the radically dissected, isolated nervous system retains these properties for several days in vitro (Chang and Gelperin, 1980; Culligan and Gelperin, 1983; A. Gelperin and N. Culligan, submitted for publication). To approach a cellular basis of plasticity in Limax, we arc delineating the groups of

${ }^{1}$ This work was supported by National Science Foundation Grant BNS 8005822 and National Institutes of Health Grant NSMN 15698 to A. G., and National Institutes of Health Training Grants 5 T32 MH15799 at Princeton University and NS-07165 at the Marine Biological Laboratory, Woods Hole, Massachusetts to $\mathrm{S}$. W. We wish to thank Dr. Frank Margolis of the Roche Institute for the use of his equipment for monoamine quantitations.

${ }^{2}$ To whom correspondence should be addressed, at the Department of Anatomy, Hahnemann University, Philadelphia, PA 19102. neurons in the cerebral ganglia which receive sensory input and those which produce feeding-control decisions which then cause the buccal motor ganglia to initiate or modulate the feeding response. A central part of this analysis is to examine the neurotransmitters which may be used to modulate feeding behavior and the interactions of these neurotransmitters with target neurons. The monoamines serotonin and dopamine are among the major neuroactive substances in molluscs, and serotonin has already been shown in several molluscs to have a powerful modulatory effect on both the neuronal feeding network and the musculature involved in feeding (Gillette and Davis, 1977; Granzow and Kater, 1977; McCrohan and Benjamin, 1980; Gelperin, 1981; Kupferman and Weiss, 1981).

Earlier studies have detected catecholamines and serotonin in the Limax nervous system, including the cerebral and buccal ganglia, which are the primary sensory and motor ganglia controlling feeding behavior (Osborne and Cottrell, 1971; Wieland and Gelperin, 1982). In this paper we present evidence suggesting a major role for 
dopamine in controlling the feeding motor system of Limax.

\section{Materials and Methods}

Specimens of $L$. maximus were maintained in laboratory culture on modified Purina Rat Chow with a lightdark cycle of 14:10 with lights on at 20:00 hr, at a temperature of $17^{\circ} \mathrm{C}$. Animals used for both biochemistry and physiology were from 5 to $10 \mathrm{gm}$ in weight. Individuals were cooled at $0^{\circ} \mathrm{C}$ for 30 min before dissection, which was carried out in Limax saline at 0 to $4^{\circ} \mathrm{C}$. Saline

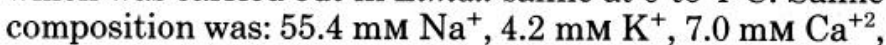
$4.6 \mathrm{mM} \mathrm{Mg}^{+2}, 80.1 \mathrm{mM} \mathrm{Cl}^{-}, 0.2 \mathrm{mM} \mathrm{H}_{2} \mathrm{PO}_{4}^{-}, 2.5 \mathrm{mM}$ $\mathrm{HCO}_{3}{ }^{-}, 5 \mathrm{mM}$ glucose, $\mathrm{pH}$ 7.6. For feeding-response physiology, the isolated lip-cerebral ganglia-buccal ganglia preparation was used, as in Chang and Gelperin (1980); for measurement of monoamine contents and synthesis, only the cerebral and buccal ganglia were retained.

Determination of dopamine and serotonin. Oxidizable monoamines were determined by modification of the methods described by Mefford (1981). Isolated ganglia were homogenized in glass with $0.3 \mathrm{ml}$ of $0.1 \mathrm{~N} \mathrm{HClO}_{4}$ in water, or in acetone containing $15 \% \mathrm{v} / \mathrm{v} 1 \mathrm{~N}$ formic acid, containing $100 \mathrm{pmol}$ of deoxyepinephrine as an internal standard. The samples were centrifuged at $5000 \mathrm{rpm}$ for $5 \mathrm{~min}$, and the supernatants were stored at $-20^{\circ} \mathrm{C}$ until assayed; recoveries averaged $80 \%$. Samples were chromatographed on a reverse-phase $\mathrm{C} 18$ column (Waters) with the following solvent system: $5 \%$ methanol, $30 \mathrm{mg}$ / liter of sodium 1-octanesulfonate, $0.1 \mathrm{~mm}$ EDTA, $0.8 \mathrm{M}$ phosphate, $\mathrm{pH} 2.8$; flow rate was $1.5 \mathrm{ml} / \mathrm{min}$. Oxidation of eluted samples at $+0.72 \mathrm{~V}$ was monitored with a Bioanalytical Systems electrochemical detector.

Metabolism of $\left[{ }^{3} \mathrm{H}\right]$ tyrosine. The production of radioactive metabolites from $\left[{ }^{3} \mathrm{H}\right]$ tyrosine was tested using the methods of Hildebrand et al (1971). Isolated ganglia were incubated at 12 to $15^{\circ} \mathrm{C}$ for up to $25 \mathrm{hr}$ in the presence of $10 \mu \mathrm{Ci} / \mathrm{ml}$ of $\left[{ }^{3} \mathrm{H}\right]$ tyrosine (specific activity $30 \mathrm{Ci} / \mathrm{mmol}$ ) in Limax saline. They were then rinsed three times in nonradioactive Limax saline and homogenized in $0.2 \mathrm{ml}$ of acetone containing $15 \% \mathrm{vol} / \mathrm{vol}$ of 1 $\mathrm{N}$ formic acid. Samples were spun at $5000 \mathrm{rpm}$ for $5 \mathrm{~min}$ in a microcentrifuge; the supernatants were dried, redissolved in $10 \mu \mathrm{l}$ of electrophoresis buffer $(0.47 \mathrm{M}$ formic acid, 1.4 $\mathrm{M}$ acetic acid, $\mathrm{pH}$ 1.9), and spotted on Whatman $3 \mathrm{MM}$ paper. The samples were subjected to $5000 \mathrm{~V}$ for approximately $1.5 \mathrm{hr}$ in a Savant electrophoresis tank and dried, and the markers were visualized with diazotized sulfanilic acid spray. The paper was cut into $1-\mathrm{cm}$ strips, acidified with $0.3 \mathrm{ml}$ of $0.01 \mathrm{~N} \mathrm{HCl}$, and counted in $5 \mathrm{ml}$ of Aqua-Sol (New England Nuclear), or BudgetSolve (Research Products International).

Histofluorescence. Isolated cerebral and buccal ganglia from Limax were frozen in powdered dry ice, sectioned $20 \mu \mathrm{m}$ thick at $-30^{\circ} \mathrm{C}$ in a cryostat, and processed with the glyoxylic acid method of de la Torre (1980). Fluorescence was visualized with epi-illumination from a 200watt mercury-vapor lamp through a Zeiss BG 12 filter and viewed through a 470-nm cut-off filter.

Physiology. The isolated lip-cerebral ganglia-buccal ganglia preparation was pinned out in a modification of the method of Gelperin et al. (1978). Three chambers were molded in a single piece of Sylgard: two flanking chambers, one for each half-lip, and the central chamber for the cerebral and buccal ganglia (Fig. 1); each chamber volume was $0.2 \mathrm{ml}$. Three lip nerves from each half-lip passed through Vaseline-sealed slits to the cerebral ganglia. Three or four polyvinyl chloride suction electrodes monitored the neural output of the buccal ganglia. Flow through the chambers was provided by three separate channels of a peristaltic pump (Rainin Rabbit) at 0.5 to $1.0 \mathrm{ml} / \mathrm{min}$. Temperature was maintained at $15^{\circ} \mathrm{C} \pm$ $0.5^{\circ} \mathrm{C}$ by Peltier refrigeration.

Drugs were applied for 2 min under constant flowing conditions; the inflow line to the ganglia passed through a temperature equilibration loop to eliminate temperature steps during drug additions. Trials were separated by at least $30 \mathrm{~min}$; lip stimulation-induced feeding motor program (FMP) responses (Gelperin et al., 1978) were periodically tested between drug trials to monitor the stability of the preparation. The order of testing of drug concentrations did not affect response properties.

Chemicals. Drug stock solutions were made fresh at 1 $\mathrm{mM}$ or $10 \mathrm{~mm}$ concentrations in $1 \mathrm{mg} / \mathrm{ml}$ of ascorbic acid. Dilutions were made in Limax saline within $2 \mathrm{~min}$ of use; $\mathrm{pH}$ measurements of the saline showed no change due to drug additions over the range used. Dopamine. $\mathrm{HCl}$, serotonin creatinine sulfate, chlorpromazine, ergo-

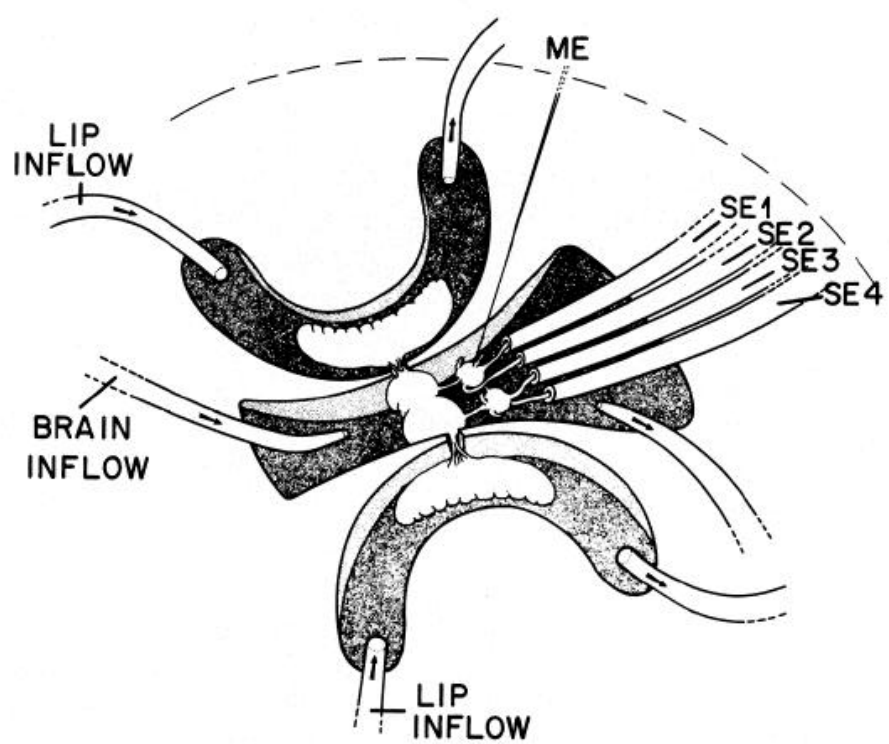

Figure 1. Schematic diagram of isolated nervous system in Limax maximus. Cerebral ganglia, buccal ganglia, and the lip chemosensory regions were left attached to one another via nerves and were dissected free of all other body structures. The two lip halves were placed in separate chambers in a multichamber unit molded in Sylgard, which allowed independent perfusion with food chemostimuli; the slits between the lip chambers and the ganglia were sealed with Vaseline. The ganglia themselves could be efficiently superfused with drugs, transmitters, or transmitter precursors. Extracellular suction electrodes (SE1, SE2, SE3, SE4) were attached to several motor nerves which exit from the buccal ganglia, and intracellular microelectrodes $(M E)$ could be placed in either cerebral or buccal neurons. 
novine, ergonovine maleate, and glyoxylic acid were purchased from Sigma Chemical Co. (St. Louis, MO). 2-Amino-6, 7-dihydroxy-1, 2, 3, 4-tetrahydronapthalene (ADTN), (+)-butaclamol, and apomorphine were purchased from Research Biochemicals Inc. (Wayland, MA). The following drugs were gifts: fluphenazine, Schering Corp. (Bloomfield, NJ); haloperidol, McNeil Pharmaceutical (Spring House, PA); lysuride, Schering AG (Berlin); LY141865, Lilly Research Laboratories (Indianapolis, IN); phentolamine, Ciba Pharmaceutical Corp. (Summit, NJ); propranolol, Ayerst Laboratories (New York, NY); RU24213 and RU24926, Roussel Uclaf (Romainville, France); spiperone, Janssen R \& D, Inc. (New Brunswick, NJ); (-)-sulpiride, Ravizza, S.P.A., (Milan, Italy); SK\&F82526 and SK\&F38393, Smith, Kline and French Laboratories (Philadelphia, PA); and bromocriptine, Sandoz Pharmaceutical (East Hanover, NJ).

\section{Results}

Presence of dopamine and serotonin in cerebral and buccal ganglia. To quantitate the catecholamine and serotonin content of ganglia controlling feeding behavior in Limax, we acid-extracted the cerebral and buccal ganglia and chromatographed the extracts using high performance liquid chromatography with electrochemical detection (HPLC-EC). This method will differentiate and detect the various catecholamines and serotonin, as these compounds are easily oxidized (Mefford, 1981). Figure 2 illustrates that ganglion extracts of Limax yielded two easily separated oxidizable components which co-chromatographed with dopamine and serotonin. No norepinephrine, epinephrine, or other metabolites of dopamine were detected. The ganglia contained large amounts of the two monoamines: $352 \pm 166(\mathrm{SD}, n=4) \mathrm{pmol}$ of serotonin and $124 \pm 33(\mathrm{SD}, n=4)$ pmol of dopamine were found in the pair of cerebral ganglia (average wet weight, $4.1 \mathrm{mg}$ ). The paired buccal ganglia (average wet weight, $1.1 \mathrm{mg}$ ) contained $29.5 \pm 17.3(\mathrm{SD}, n=4)$ pmol of serotonin and $19.4 \pm 2.4(\mathrm{SD}, n=4)$ pmol of dopamine. Four other determinations without internal standards corroborated these values. From the standard deviations there appeared to be a much larger interanimal variance in serotonin values than in dopamine values. This was probably not due to variance in the recovery of serotonin, because cerebral and buccal ganglion serotonin values varied in parallel in samples from the same animal; a low buccal ganglion serotonin value predicted a low cerebral ganglion serotonin value.

As an independent confirmation of the presence of a dopaminergic system, we tested the ability of the ganglia to synthesize products from $\left[{ }^{3} \mathrm{H}\right]$ tyrosine (Fig. 3). Both the cerebral and buccal ganglia produced $\mathrm{a}^{3} \mathrm{H}$ component which co-electrophoresed with authentic dopamine. Incubation times from 1 to $24 \mathrm{hr}$ were used; longer incubation times produced larger quantities of labeled dopamine. Little evidence for the synthesis of either norepinephrine or octopamine was seen at any time point; however, the presence of either transmitter at a very low level is not ruled out.

Cells and neuropil exhibiting glyoxylic acid-induced fluorescence were found in both the buccal and cerebral
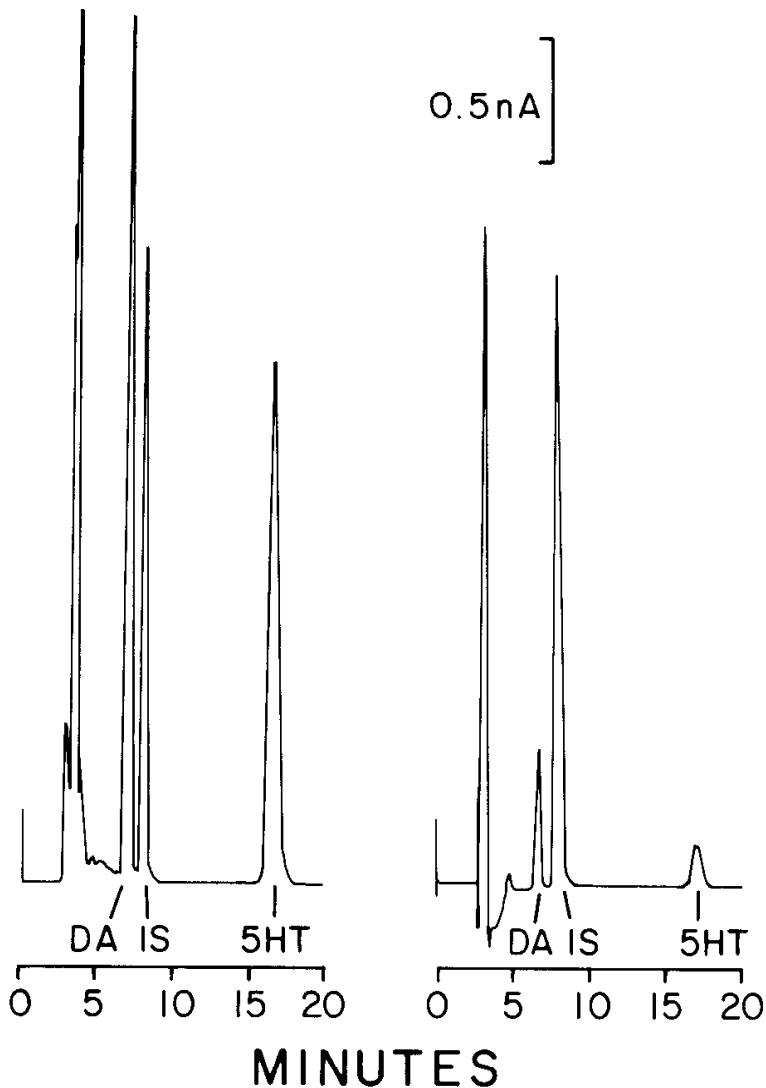

Figure 2. Quantitation of monoamines in Limax CNS extracts by HPLC-EC. Samples were extracted and chromatographed as described under "Materials and Methods." Left, 50 $\mu \mathrm{l}$ of a $300-\mu \mathrm{l}$ extract from one pair of cerebral ganglia. Right, $50 \mu \mathrm{l}$ of a $300-\mu$ l extract from one pair of buccal ganglia. $D A$, dopamine; $I S$, internal standard deoxyepinephrine; $5 H T$, serotonin.

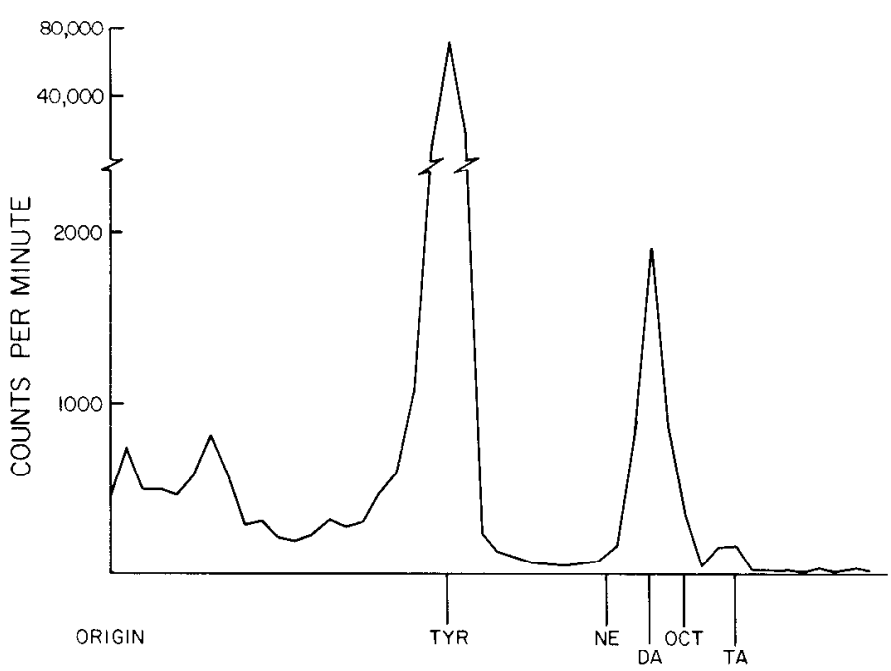

Figure 3. Synthesis of monoamines from $\left[{ }^{3} \mathrm{H}\right]$ tyrosine by cerebral ganglia of Limax. Cerebral ganglia from a specimen of L. maximus were incubated in $10 \mu \mathrm{Ci} / \mathrm{ml}$ of $\left[{ }^{3} \mathrm{H}\right]$ tyrosine $(3 \times$ $10^{-7} \mathrm{M}$ ) in $\operatorname{Limax}$ saline for $24 \mathrm{hr}$ at $11^{\circ} \mathrm{C}$. The ganglia were then rinsed three times with saline, extracted, and subjected to high voltage paper electrophoresis as described under "Materials and Methods." TYR, tyrosine; $N E$, norepinephrine; $D A$, dopamine; $O C T$, octopamine; $T A$, tyramine. 
ganglia (Fig. 4). This fluorescence was both heat and glyoxylic acid dependent; virtually all of the intensely fluorescent cells were relatively small, occurred in clusters, and exhibited the green-yellow fluorescence indicative of catecholamines. In Figure $4 A$, three clusters are apparent in a $20-\mu \mathrm{m}$ section of the cerebral ganglion (arrows). The lowest cluster gave rise to fluorescent fibers which projected out the external lip nerve, and the middle cluster projected out the internal lip nerve; the connections of the upper cluster are not known at this time. The serotonin-containing metacerebral giant cell (Fig. $4 A$, arrowhead) is also visible in this section; the yellow fluorescence of the glyoxylic adduct of serotonin was much weaker than that of dopamine. This may be due to the weaker fluorescent yield of serotonin with glyoxylic acid (Moore, 1981) or to a low level of serotonin in the soma relative to the neurites. However, the yellow serotonin fluorescence was clearly differentiated from the dull red background fluorescence. Figure $4 B$ shows cross-sections through 4 of the approximately 10 small green-yellow fluorescent cells in the buccal ganglion. Thus, in addition to the known distribution of serotonin, dopamine is also integrally associated in both the sensory

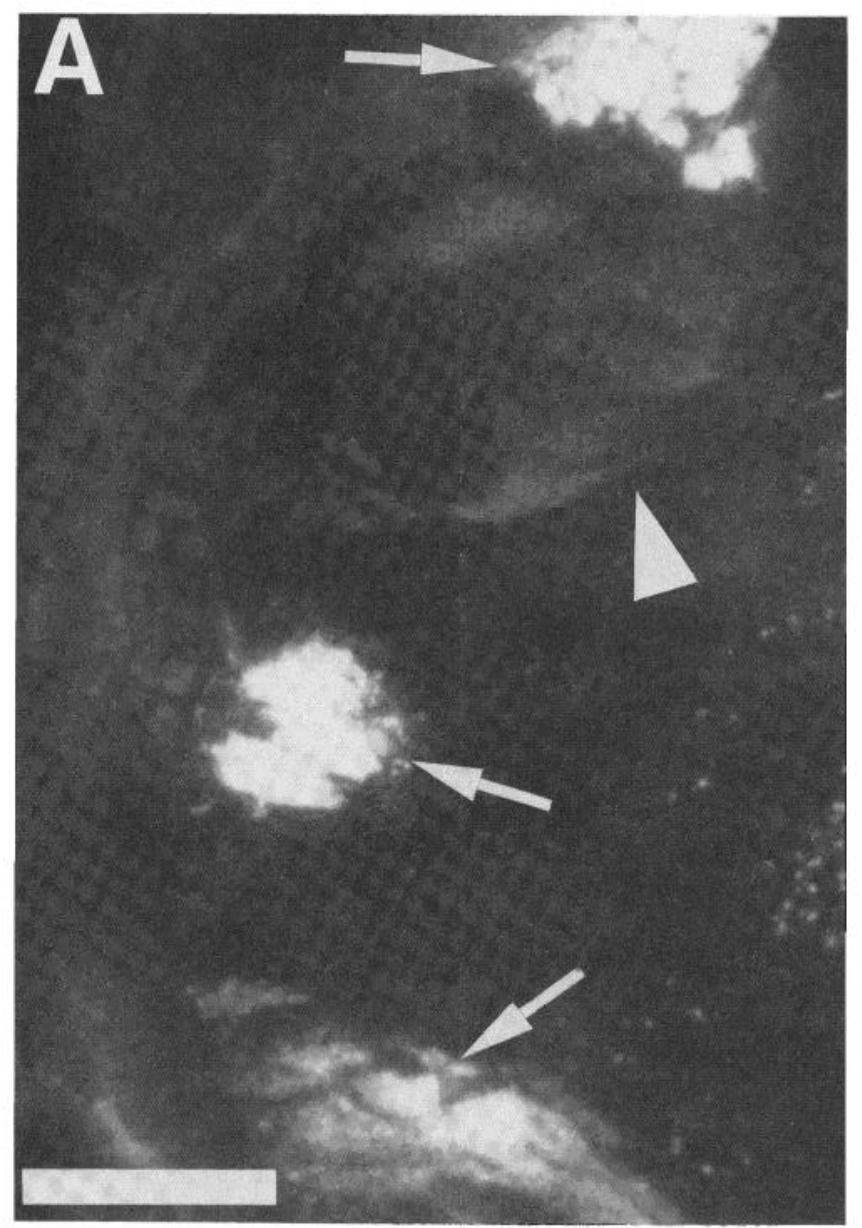

and motor ganglia with cells or structures underlying feeding behavior.

Dopamine target cells. Inasmuch as significant amounts of dopamine are present in the sensory and motor ganglia controlling feeding, dopamine might play an important role in the mediation of feeding behavior. We are seeking to identify major effects of dopamine and to identify both dopaminergic and target cells, if possible. As a first step, we examined the effects of exogenous dopamine on the feeding network and compared the dopamine-induced activity to the feeding motor program induced by lip chemostimulation. We also compared both of these effects to those of exogenously applied serotonin.

In an unstimulated preparation, most units projecting out the buccal roots are quiescent, except two burstfiring cells in the salivary nerve. Exogenous dopamine in the concentration range of $10^{-7} \mathrm{M}$ to $3 \times 10^{-6} \mathrm{M}$ produced overt effects on these two motor neurons (Fig. 5). The autoactive fast salivary burster cell (FB), which controls salivary duct contractions (Prior and Gelperin, 1977; Beltz and Gelperin, 1980a, b), was excited. In Figure 5, the interburst interval of the right FB declined from 13 sec to 7 sec during dopamine exposure; the left FB

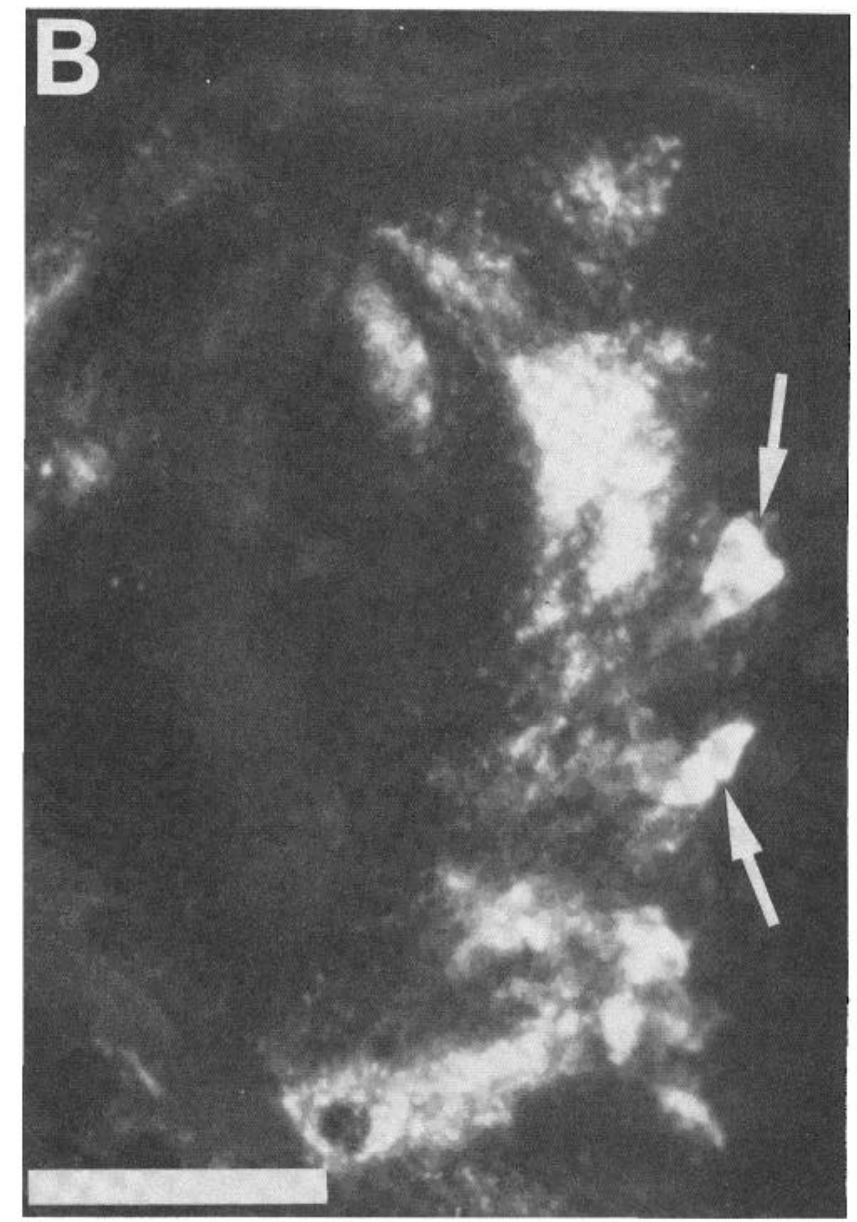

Figure 4. Induced fluorescence of catecholamine and serotonin-containing cells in Limax. A is a section through a cerebral ganglion; the other cerebral ganglion is outside the frame to the left of the area shown, and the buccal ganglia are outside the frame, below the area shown. The metacerebral giant cell is the large, dimly fluorescent cell (arrowhead); bright green-yellow fluorescent clusters of cells (arrows) are shown above and below the metacerebral cell. $B$ is a section through a buccal ganglion illustrating several fluorescent cells (arrows) and fluorescent neuropil. Scale bars are $100 \mu$ long. 


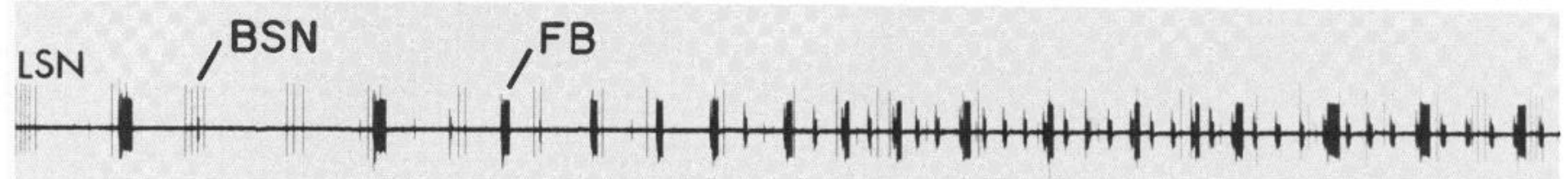

R3

R1

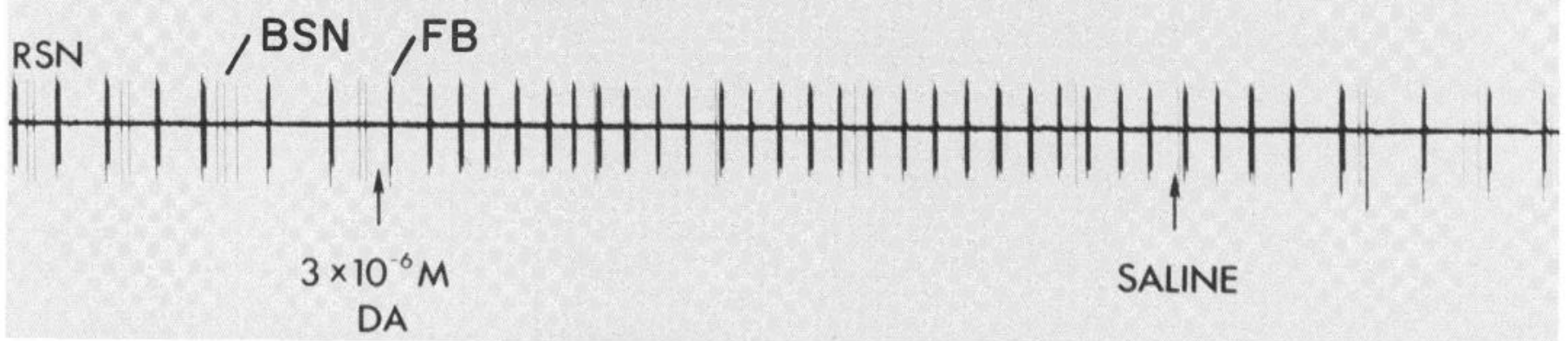

Figure 5. Selective excitation by dopamine of the buccal feeding network in Limax. Dopamine-containing saline was substituted for standard saline in a flow-through chamber containing a cerebral ganglion-buccal ganglion system. Extracellular recordings from the left salivary nerve $(L S N)$ and right salivary nerve $(R S N)$ show an increased number of bursts per unit time of the fast salivary burster neuron $(F B)$. Each burst contains several unresolved spikes: 30 to 33 spikes/burst in LFB, 9 to 10 spikes/burst in RFB before dopamine; 22 to 25 spikes/burst in LFB, 7 to 9 spikes/burst in RFB during dopamine perfusion. The single, resolved spikes in LSN and RSN are from the slow salivary bursters $(B S N)$; both the left and right BSN show inhibition of bursting during dopamine perfusion. Extracellular recordings from other buccal motor nerve roots show that no monitored neural activity exhibits excitation. $R 3$, right buccal root $3 ; R 1$, right buccal root 1 . Flow rate was $500 \mu \mathrm{l} / \mathrm{min}$.

interval declined from one burst every $65 \mathrm{sec}$ to one burst every $20 \mathrm{sec}$ in the presence of dopamine. In data pooled from six preparations, the burst frequency of FB increased in a concentration-dependent manner during dopamine exposure up to $10^{-5} \mathrm{M}$ dopamine (Fig. 6). Although the excitatory effect of $10^{-7} \mathrm{M}$ dopamine on FB was significantly above base line, we have not yet tried lower concentrations to determine a threshold. Above 3 $\times 10^{-6} \mathrm{M}$, dopamine sometimes triggered the feeding motor program (see below), which set the FB burst frequency to the cycle rate of the motor program; thus the $\mathrm{FB}$ burst rate at $5 \times 10^{-5} \mathrm{M}$ (where feeding was always triggered) in Figure 6 is lower than at $10^{-5} \mathrm{M}$.

The slow-bursting "bilateral salivary neuron" (BSN) of the buccal ganglion bifurcates and innervates both the ipsilateral and contralateral salivary glands through the salivary nerves (Copeland and Gelperin, 1983). In contrast to FB, BSN showed inhibition by exogenous dopamine (Figure 5). This result was seen in at least 12 experiments in which BSN spikes were resolvable in the salivary nerves, although the data are not yet sufficient to generate a concentration response curve. The left salivary nerve trace in Figure 5 shows that the BSN fired a burst of three to five spikes every 19 to $24 \mathrm{sec}$ in normal saline. By the last $60 \mathrm{sec}$ of dopamine exposure, five isolated spikes with no clear burst pattern were recorded, indicating clear inhibition and depression of burst firing. Likewise, the record of the right salivary nerve also shows inhibition of the other BSN. From pre-exposure bursts of two to three spikes every 24 to $26 \mathrm{sec}$, the neuronfiring pattern declined to a single spike during the final $60 \mathrm{sec}$ of dopamine exposure. In other cases, burst firing itself was not abolished, but the interburst intervals were still significantly lengthened (e.g., Fig. 8).

The effects of exogenous dopamine on these two neurons exhibited rapid onset and little desensitization with time. Excitation of the fast burster usually reached maximum in approximately $30 \mathrm{sec}$ and was maintained as long as 20 min with continuous dopamine perfusion. Ascorbic acid alone at $5 \times 10^{-5} \mathrm{M}$, twice its maximal concentration in any superfusion solution, had no effect after 40 min exposure.

Intracellular monitoring of FB (Fig. 7) during dopamine exposure in normal saline showed far less interburst hyperpolarization than in the absence of dopamine. Individual bursts tended to be more irregular and have fewer spikes during dopamine excitation. In Figure 7, many of the bursts contained only two or three spikes, 


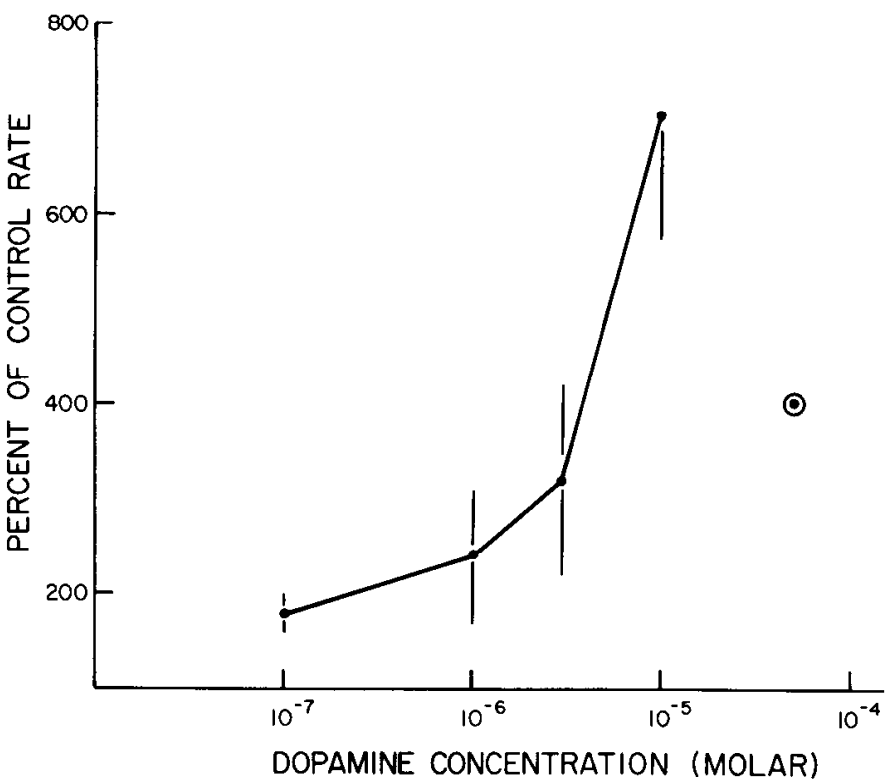

Figure 6. Effect of exogenous dopamine on fast burster neuron activity. Exogenous dopamine was added to isolated nervous systems as in Figure 5 . The resulting burst frequency was defined as the number of bursts during the period between 60 and $120 \mathrm{sec}$ after the beginning of the constant infusion of dopamine through the chamber. The control value for each run was the burst rate of the last $60 \mathrm{sec}$ before dopamine infusion; average burst frequency in the absence of dopamine was 4.5 bursts/min. The average burst frequency dropped at dopamine concentrations above $10^{-5} \mathrm{M}$ because the feeding motor program was reliably triggered (see Table I). Synchronization of the network during expression of the feeding motor program resulted in lower burst frequencies at $5 \times 10^{-5} \mathrm{M}$.
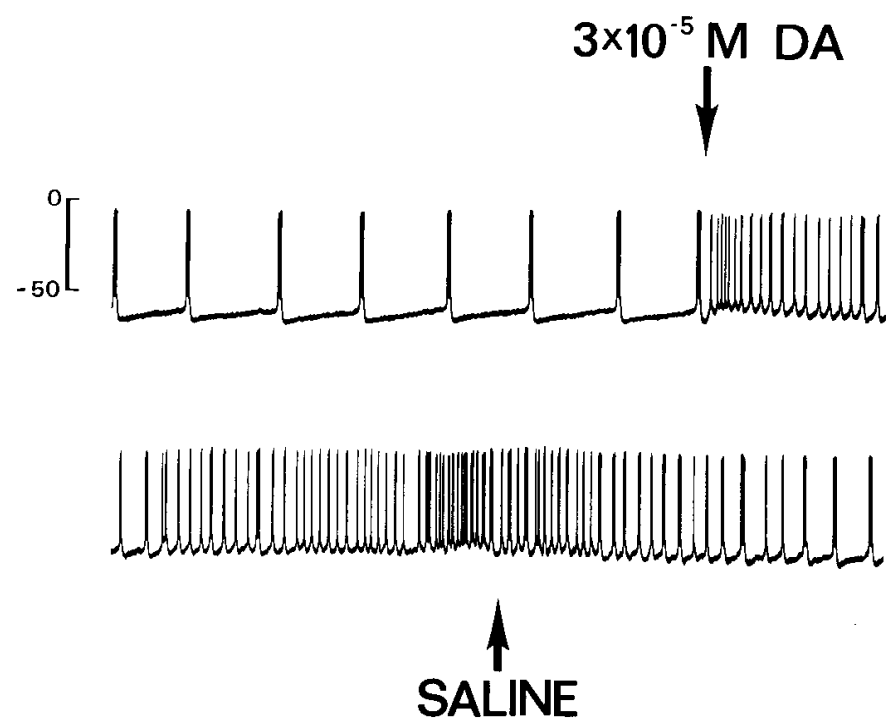

\section{SECONDS}

Figure 7. FB response during exposure to dopamine. Continuous intracellular record of FB activity before, during, and after exposure to $3 \times 10^{-5} \mathrm{M}$ dopamine in normal Limax saline. FB showed depolarization of the interburst interval and a highly increased rate of bursting during exposure to dopamine. Reversal of excitation was visible starting 30 to $60 \mathrm{sec}$ after normal saline alone began flowing through the chamber. compared to 11 to 12 spikes per burst before dopamine exposure. However, dopamine increased the average spike frequency of FB from 48 to 140 spikes $/ \mathrm{min}$.

Both the excitatory and inhibitory effects persisted in low $\mathrm{Ca}^{2+}$-high $\mathrm{Mg}^{2+}$ saline $\left(0.5 \mathrm{mM} \mathrm{Ca}{ }^{2+}, 18 \mathrm{mM} \mathrm{Mg}{ }^{2+}\right)$ which blocked chemical synapses (Prior and Gelperin, 1977; Prior and Grega, 1982), suggesting that the dopamine effects were directly on $\mathrm{FB}$ and $\mathrm{BSN}$ or on cells tightly electrically coupled to them (seven trials in three preparations). After $15 \mathrm{~min}$ in low calcium saline the autoactive cells had stabilized at new rates; the illustrated test of dopamine sensitivity in low calcium saline (Fig. 8) was run after $45 \mathrm{~min}$. In the extracellular trace (Fig. 8, top), the slow bursts of both the ipsilateral BSN (larger spikes) and the contralateral BSN (smaller spikes) were visible (the contralateral BSN spikes are not detected in all salivary nerves due to their smaller size). Superfused dopamine at $3 \times 10^{-5} \mathrm{M}$ clearly decreased the interburst interval of the FB cell (Fig. 8, bottom) and strongly delayed the bursts of the BSNs (Fig. 8, top). The FB response to dopamine was not as extreme as in normal saline, perhaps due to the changed bursting properties which accompanied exposure to the modified saline.

Dopamine elicits expression of the feeding motor program in vitro. Tests were conducted with the isolated lipcerebral ganglia-buccal ganglia preparation in order to directly compare the lip-stimulated cyclic, synchronized bursting pattern of the buccal motor units, which has been identified as the feeding motor program (FMP, Gelperin et al., 1978), with dopamine-stimulated outputs. Concentrations of dopamine above $3 \times 10^{-6} \mathrm{M}$ triggered FMP in the isolated preparation (Fig. 9). The dose dependency of the probability of triggering FMP (an allor-none event for each 2-min trial) was measured in six preparations by scoring for each of several trials whether a given concentration of dopamine elicited FMP. This probability increased smoothly over the concentration range tested (Table I). In all cases, units monitored in the motor roots showed similar phase relations and firing frequencies in dopamine-excited and lip-stimulated feeding. In three cases, dopamine applied to buccal ganglia isolated from the cerebral ganglia also elicited rhythmic motor output similar to FMP, indicating that major targets of dopamine were present in the buccal network itself; however, in the absence of the cerebral connective, direct comparison with lip-stimulated feeding was not possible in these preparations.

Dopamine agonist and antagonist effects. Exogenous ADTN, a rigid analogue of dopamine, was equipotent with dopamine over the range $10^{-7} \mathrm{M}$ to $10^{-5} \mathrm{M}$ (Table II). The compound SK\&F38393, a dopamine D1 receptor agonist in vertebrates (Stoof and Kebabian, 1981), and an analogue, SK\&F82526, were also relatively potent in producing a dopaminergic effect in Limax. Lower concentrations $\left(10^{-5} \mathrm{M}\right)$ excited $\mathrm{FB}$ and inhibited BSN, whereas higher concentrations (above $10^{-4} \mathrm{M}$ ) triggered the feeding motor program. Apomorphine, bromocriptine, and the vertebrate D2 agonists lysuride (Kebabian and Calne, 1979) and RU24213 and RU24926 (Euvrard et al., 1980) were ineffective on FB, BSN, and the Limax feeding system. 


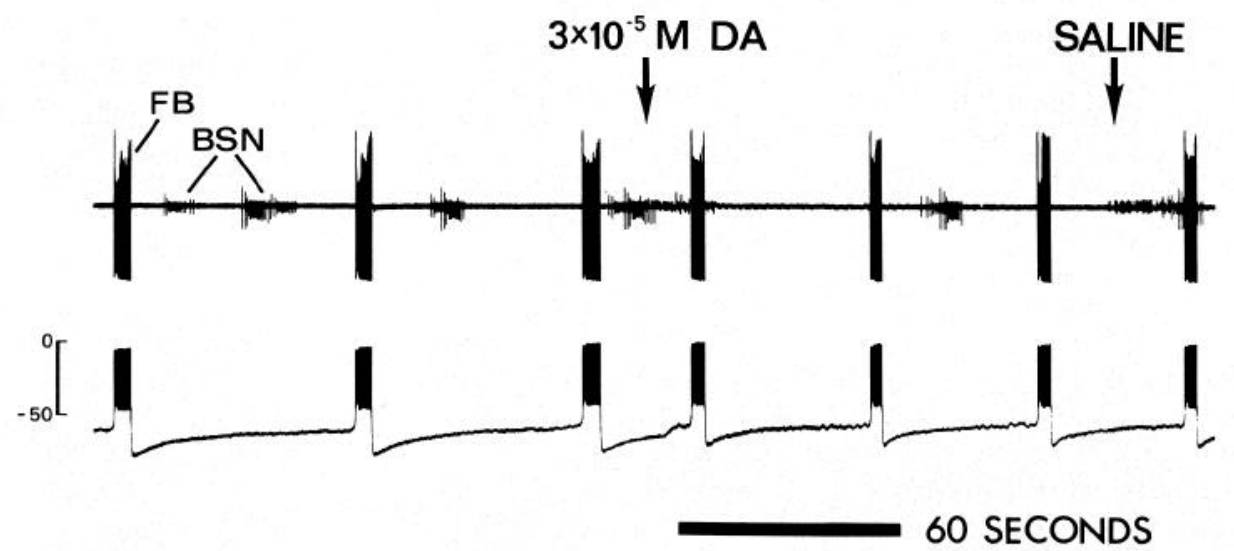

Figure 8. Effect of dopamine in low $\mathrm{Ca}^{2+}$, high $\mathrm{Mg}^{2+}$ saline. An intracellular electrode monitored the right FB (lower trace) while an extracellular electrode monitored the activity of the right $\mathrm{FB}$ and both BSNs in the right salivary nerve (upper trace) of the same preparation shown in Figure 7. In normal saline, both BSNs had 8 to 10 spikes/ burst with a 22 - to 30 -sec interburst interval. In modified saline $\left(0.5 \mathrm{mM} \mathrm{Ca}^{2+}, 18 \mathrm{~mm}\right.$ $\mathrm{Mg}^{2+}$ ), the BSNs stabilized at 16 to 20 spikes/burst, with interburst intervals of 30 to 50 sec. FB stabilized at 80 to 85 spikes/burst after $15 \mathrm{~min}$, with a 61 - to 65 -second interburst interval. FB showed hyperpolarization to $-78 \mathrm{mV}$ at the end of each burst. Dopamine perfusion reduced the FB interburst interval to $29 \mathrm{sec}$ for the first, then 40 to $48 \mathrm{sec}$ for the remaining intervals. Both BSNs showed delays of $86 \mathrm{sec}$ after dopamine exposure before their next bursts.

\section{LSN}
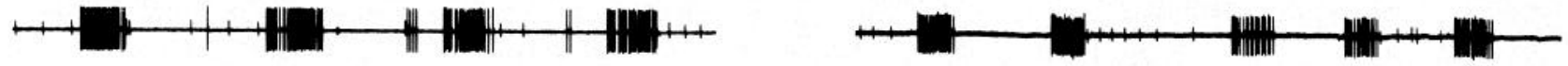

L1
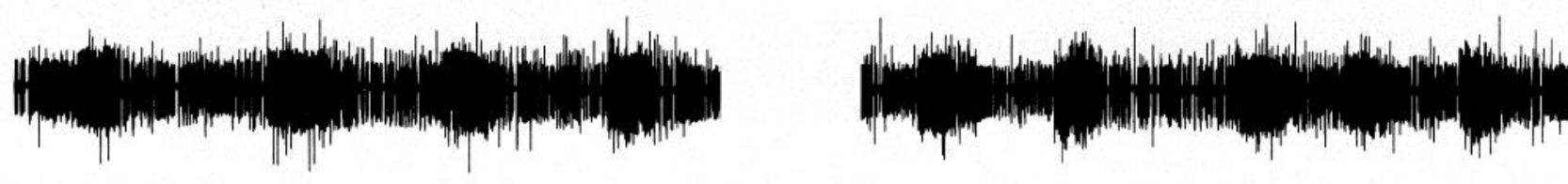

RSN
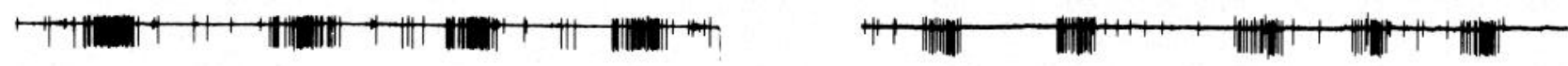

B 10
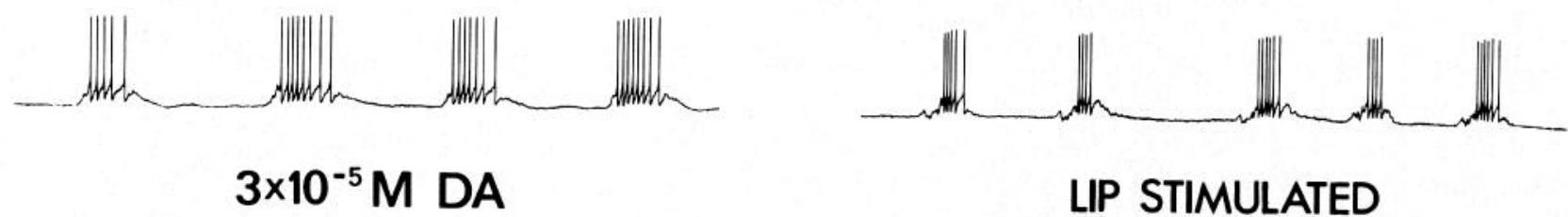

LIP STIMULATED

10 SECONDS

Figure 9. Comparison of cycles of the feeding motor program (FMP) induced by exogenous dopamine and lip-stimulated FMP in the same preparation. Left, Dopamine $\left(3 \times 10^{-5} \mathrm{M}\right)$ applied to the nervous system triggered a synchronized oscillatory response monitored in the buccal motor roots. An intracellular recording of an identified buccal neuron (B10) showed smooth recruitment into the phase-locked feeding in a similar pattern to that seen in chemostimulus-induced feeding. Right, Lip-stimulated feeding motor program in the same preparation. Both lips were stimulated by $20 \mathrm{sec}$ of diluted apple juice (50\% in saline). $L S N$, left salivary nerve; $R S N$, right salivary nerve; $L 1$, left buccal root 1 . 
TABLE I

Induction of FMP by dopamine

\begin{tabular}{rcr}
\hline Dopamine Concentration & $\begin{array}{c}\text { Episodes of FMP/ } \\
\text { No. of Trials }\end{array}$ & Percentage \\
\hline $10^{-6} \mathrm{M}$ & $0 / 7$ & 0 \\
$3 \times 10^{-6} \mathrm{M}$ & $1 / 6$ & 17 \\
$10^{-5} \mathrm{M}$ & $5 / 15$ & 33 \\
$5 \times 10^{-5} \mathrm{M}$ & $9 / 9$ & 100 \\
\hline
\end{tabular}

The ergot alkaloid ergonovine was a potent dopamine antagonist (Table II). At a concentration of $10^{-6} \mathbf{M}$, ergonovine or ergonovine maleate prevented excitation of $\mathrm{FB}$, inhibition of BSN, or induction of FMP by concentrations of dopamine up to $3 \times 10^{-5} \mathrm{M}$ (15 trials in seven preparations). Serotonin, which excites many neurons in the buccal ganglion (see final section), was more weakly blocked by ergonovine (eight trials in four preparations). The excitation of FB (measured as bursts per minute) produced by $10^{-5} \mathrm{M}$ serotonin was reduced by approximately $50 \%$ in $5 \times 10^{-6} \mathrm{M}$ ergonovine, and excitation by $3 \times 10^{-5} \mathrm{M}$ serotonin was unaffected by $3 \times$ $10^{-6} \mathrm{M}$ ergonovine. These results indicate that dopamine was much more susceptible to blockade by ergonovine than serotonin and that ergonovine did not induce nonspecific inexcitability, because serotonin could produce excitation in its presence.

The vertebrate dopamine receptor blocking drugs (+)butaclamol, haloperidol, spiperone, and fluphenizine, were ineffective at $10^{-5} \mathrm{M}$ in showing any inhibition of the effects of $3 \times 10^{-6} \mathrm{M}$ dopamine. In addition, phentolamine (an $\alpha$-adrenergic blocker) and propranolol (a $\beta$ adrenergic blocker) were also ineffective at $10^{-5} \mathrm{M}$ in inhibiting $3 \times 10^{-6} \mathrm{M}$ dopamine.

Ergonovine blocks expression of the feeding motor program in vitro. Ergonovine was a potent blocking agent of changes in neuronal activity induced by exogenous dopamine, including excitation of $\mathrm{FB}$, inhibition of BSN, and induction of FMP. Therefore, we tested a possible role of dopamine in the expression of FMP in response to lip chemostimulation by food extracts in vitro by attempting to inhibit this response with ergonovine (five trials in three preparations). Application of 0.5 to $5 \times$ $10^{-6} \mathrm{M}$ ergonovine maleate or ergonovine inhibited lip stimulus-induced expression of FMP in each case. Figure $10 \mathrm{~A}$ illustrates the normal response of an isolated preparation to $15 \mathrm{sec}$ of lip stimulation with a saline extract of potato. The cerebral and buccal ganglia of this same preparation were then exposed to $5 \times 10^{-6} \mathrm{M}$ ergonovine maleate starting $90 \mathrm{sec}$ before lip stimulation (Fig. 10B). The response to potato stimulation was then severely inhibited; two weak "bite" cycles were completed, and even these showed fewer units firing than the nontreated test (Fig. 10A). Lower concentrations of ergonovine produced partial inhibition of the feeding response: at $0.5 \times$ $10^{-6} \mathrm{M}$ of ergonovine maleate, the number of bite cycles in response to $15 \mathrm{sec}$ of lip stimulation was $25 \%$ of the control response.

Both onset and recovery times with ergonovine treatment were slower than with other drugs. With dopamine already present in the bathing medium, added ergonovine took up to $60 \mathrm{sec}$ to block dopamine stimulation. Likewise, complete removal of the blockade took 30 to $60 \mathrm{~min}$
TABLE II

Feeding system response to dopamine drugs

\begin{tabular}{lcc}
\hline \multicolumn{1}{c}{ Agonist } & $\begin{array}{c}\text { Relative } \\
\text { Potency }^{a}\end{array}$ & $\begin{array}{c}\text { No. of } \\
\text { Tests }\end{array}$ \\
\hline Dopamine & +++ & $>60$ \\
ADTN & +++ & 8 \\
SKF38393 & ++ & 10 \\
SKF82526 & ++ & 3 \\
LY141865 & - & 4 \\
Apomorphine & - & 2 \\
Bromocriptine & - & 3 \\
Lysuride & - & 3 \\
\hline \multicolumn{1}{c}{ Antagonist } & Relative & No. of \\
\hline Ergonovine & Potency & Tests \\
Spiperone & +++ & 15 \\
Sulpiride & + & 14 \\
(+)-Butaclamol & - & 4 \\
Haloperidol & - & 9 \\
Fluphenazine & - & 2 \\
Chlorpromazine & - & 3 \\
Phentolamine & - & 3 \\
Propranolol & - & 7 \\
\hline
\end{tabular}

${ }^{a}$ Approximate potency: +++ , most potent drug (see the text for numbers);,$++ 10 \%$ as potent;,$+ 1 \%$ as potent; - , ineffective even at high concentration.

for low concentration $\left(10^{-6} \mathrm{M}\right)$ ergonovine treatments and up to $5 \mathrm{hr}$ for $5 \times 10^{-6} \mathrm{M}$ ergonovine effects to be fully reversed.

Contrast of serotonin and dopamine effects. Since serotonin also exerts excitatory effects in the feeding system (Gelperin, 1981), this monoamine was applied to isolated preparations in the identical manner as dopamine (18 trials in five preparations). Under these conditions, the effects of serotonin could be distinguished from those of dopamine in four ways: (1) serotonin $\left(10^{-7} \mathrm{M}\right.$ to $10^{-5} \mathrm{M}$ ) excited BSN as well as FB (Fig. 11), whereas dopamine inhibited BSN and excited FB (Fig. 5); (2) serotonin $\left(10^{-7} \mathrm{M}\right.$ to $\left.10^{-5} \mathrm{M}\right)$ excited several motor units in other buccal roots (Fig. 11), whereas dopamine did not (Fig. 5) unless FMP was triggered; (3) serotonin at greater than $10^{-5} \mathrm{M}$ elicited hroad excitation of multiple buccal motor units, but these exhibited little or none of the synchronization found in the feeding motor program (Gelperin, 1981); (4) serotonin effects were more weakly blocked by ergonovine than dopamine effects (see "Dopamine agonist and anlagonisl effects").

\section{Discussion}

Dopamine and serotonin are major neuroactive chemicals in both invertebrates and vertebrates (Jacobs and Gelperin, 1981). Serotonin plays a role in exciting several invertebrate behaviors, for example, stimulating the flexed posture of the lobster (Livingston et al., 1980), swimming behavior in the leech (Willard, 1981), sensitizing the gill withdrawal reflex of Aplysia (Kandel and Schwartz, 1982; Siegelbaum et al., 1982), and intensifying the feeding behavior of several molluscs (Kupfermann and Weiss, 1981; Gelperin, 1981).

The behavioral roles of dopamine are not yet as extensively documented in invertebrates. However, it has been found to be a strong positive modulator of the pyloric 
A

L1

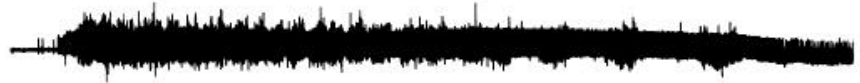

LSN

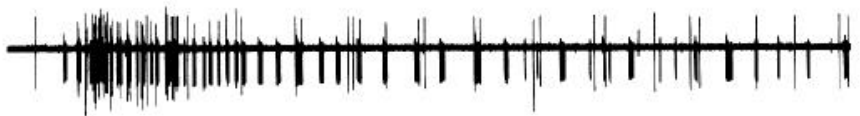

RSN

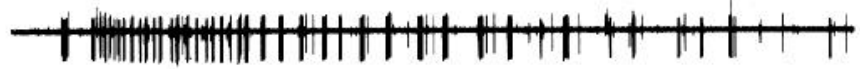

R2

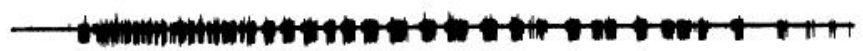

1

15 SEC POTATO
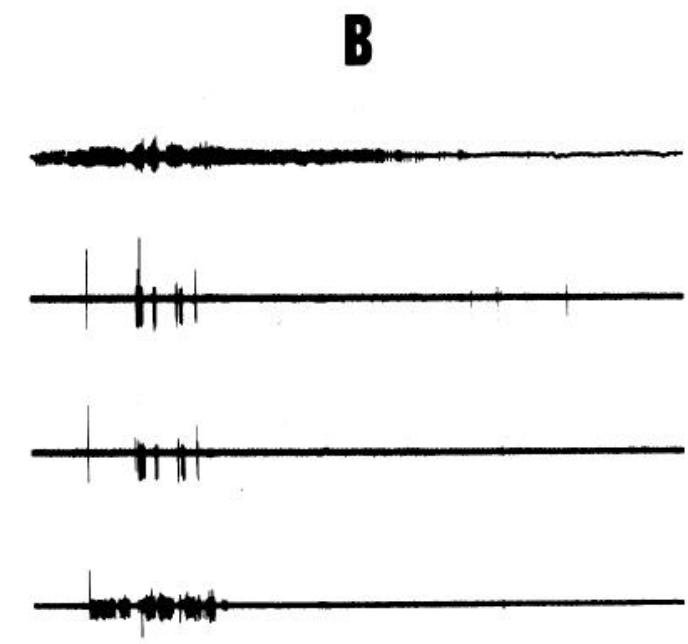

$\uparrow$

15 SEC POTATO

\section{SECONDS}

Figure 10. Blockade of feeding response by ergonovine. A, A standard lip-cerebral ganglion-buccal ganglion preparation was stimulated by the application of $15 \mathrm{sec}$ of a saline extract of potato to the lips. The entire response of feeding motor program is illustrated. $B$, The cerebral and buccal ganglia of the same preparation as in $A$ were exposed to $5 \times 10^{-6} \mathrm{M}$ ergonovine maleate in saline continuously, starting $90 \mathrm{sec}$ before the arrival of a potato stimulus to the lips. The resulting response to the lip stimulus is illustrated. $L 1$, left buccal root $1 ; L S N$, left salivary nerve; $R S N$, right salivary nerve; $R 2$, right buccal root 2 .

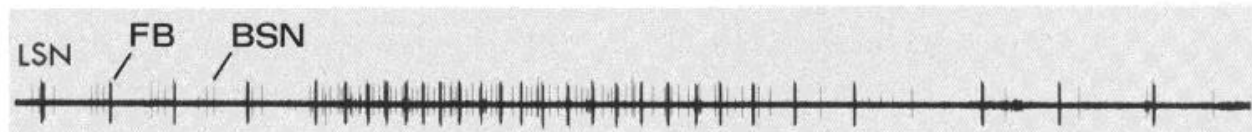

R3

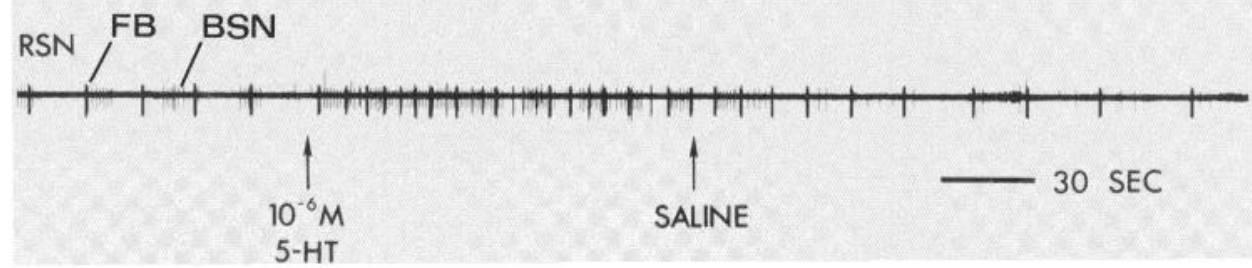

Figure 11. Serotonin excitation of the buccal feeding network in Limax. Serotonincontaining saline was substituted for standard saline in a flow-through chamber containing a cerebral ganglion-buccal ganglion system as in Figure 5. Extracellular recordings from buccal motor nerve roots show that all monitored neural roots exhibited excitation. $L S N$, left salivary nerve; $R 3$, right buccal root $3 ; R S N$, right salivary nerve; $F B$, fast burster neuron; $B S N$, bilateral salivary neuron; $5-H T$, serotonin.

rhythm in the lobster stomatogastric ganglion (Kushner and Maynard, 1977; Barker et al., 1979; Anderson and Barker, 1981). Our data, and those of Trimble and Barker (1982) in Helisoma, bring dopamine into consideration for a major modulatory or command role in molluscan feeding behavior. The effect of dopamine on the stomatogastric network and on the buccal network is excitatory and shows little desensitization, in contrast to the desensitization of excitatory and inhibitory effects seen in single-neuron studies of dopamine effects in Aplysia (Ascher, 1972).

Two identified potential target cells for dopamine were found in the buccal ganglion. Extracellular monitoring indicated that the autoactive "bilateral" slow burster neuron (Copeland and Gelperin, 1983) and the salivary fast burster motor neuron (Prior and Gelperin, 1977; Beltz and Gelperin, 1980a, b) were oppositely affected by superfused dopamine: BSN was inhibited, and FB was 
excited. The excitation of the autoactive bursting cell FB by dopamine appears to be a novel finding; however, the inhibitory effects of dopamine on BSN may have a parallel in the inhibition of Aplysia R15 bursting by dopamine. Dopaminergic inhibition of R15 has in turn been compared to "long duration synaptic inhibition" (Boisson and Gola, 1976; Wilson and Wachtel, 1978; Adams et al., 1980; Gospe and Wilson, 1980). In R15, it has been argued that at least part of the long duration synaptic inhibition as well as dopamine-induced inhibition was mediated by a decrease in slow sodium and/or calcium conductances, whereas a shorter term component of inhibition was mediated by a potassium conductance increase (Wilson and Wachtel, 1978; Adams et al., 1980). A study of the mechanisms of dopamine action on BSN and FB may provide models for the modulation of the rest of the feeding network in $L$. maximus.

There may also be a parallel between dopamine's inhibitory action on BSN and its effect on some hippocampal pyramidal neurons. Dopamine's action on BSN is to shorten bursts and lengthen interburst intervals (Fig. 5). Bernardo and Prince (1982) showed that dopamine augments the postspike hyperpolarization when applied to guinea pig hippocampal pyramidal neurons, probably by interaction with the adenylate cyclase-linked D1 receptor (Iversen, 1975; Seeman, 1980). Since some hippocampal pyramidal neurons normally fire rhythmic bursts of action potentials (Kandel and Spencer, 1961; Wong and Prince, 1978), it seems likely that dopamine application to such bursting hippocampal neurons would also shorten each burst and lengthen the interburst intervals, as it does to BSN.

The role of dopamine in modulating the feeding behavior of Limax is not limited to the buccal system; a large amount of dopamine is present in the cerebral ganglia. Fluorescent adducts of dopamine and serotonin reveal an extensive system of cerebral neurons which project to the lips (Osborne and Cottrell, 1971; Wieland and Gelperin, 1982) as well as other cells whose projections have not been mapped. The roles of these cells in feeding behavior have not yet been determined.

In vitro ligand-binding studies of vertebrate tissues have defined at least four forms of dopamine-binding sites (Seeman, 1980). However, only two major categories of vertebrate dopamine receptors have been defined on the basis of response physiology (Kebabian and Calne, 1979; Creese et al., 1983). One apparently stimulates adenylate cyclase (D1), whereas the other (D2) does not stimulate and may even inhibit it. Certain agonists and antagonists can affect D1 model systems and D2 model systems quite differently (Stoof and Kebabian, 1981). Our survey of agonists and antagonists suggests that the Limax feeding system responses to various dopamine agonists are similar to those of a vertebrate D1 receptor. However, these responses cannot be blocked by standard vertebrate dopamine antagonists. The only potent antagonist we have found thus far is ergonovine. Ergonovine, also known as ergometrine, has been noted as a dopaminergic antagonist in several molluses: Planorbis corneus (Cottrell et al., 1974), Helix aspersa (Walker et al., 1968), and Aplysia (Ascher, 1972). One interpretation of these data is that the molluscan dopamine agonist-bind- ing site is similar to the vertebrate D1 dopamine agonistbinding site but that the antagonist-binding sites of molluses and vertebrates have dissimilar requirements. This description leaves open the question of whether the agonist- and antagonist-binding sites are truly separate but allosterically linked or are two conformations of the same site. It also suggests that if endogenous antagonists for dopamine receptors exist, they may be different molecules in vertebrates and molluscs.

\section{References}

Adams, W. B., I. Parnas, and I. B. Levitan (1980) Mechanism of long-lasting synaptic inhibition in Aplysia neuron R15. J. Neurophysiol. 44: 1148-1160.

Anderson, W. W., and D. L. Barker (1981) Synaptic mechanisms that generate network oscillations in the absence of discrete postsynaptic potentials. J. Exp. Zool. 216: 187-191.

Ascher, P. (1972) Inhibitory and excitatory effects of dopamine on Aplysia neurones. J. Physiol. (Lond.) 225: 173-209.

Barker, D. L., P. D. Kushner, and N. K. Hooper (1979) Synthesis of dopamine and octopamine in the crustacean stomatogastric nervous system. Brain Res. 161: 99-113.

Beltz, B., and A. Gelperin (1980a) Mechanosensory inputs modulate the activity of salivary and feeding neurons in Limax maximus. J. Neurophysiol. 44: 665674.

Beltz, B., and A. Gelperin (1980b) Mechanisms of peripheral modulation of salivary and feeding neurons in Limax maximus: A presumptive sensory-motor neuron. J. Neurophysiol. 44: 675-686.

Bernardo, L. S., and D. A. Prince (1982) Dopamine action on hippocampal pyramidal cells. J. Neurosci. 2: 415-423.

Boisson, M., and M. Gola (1976) Current-voltage relations in ILD- or dopamine-stabilized bursting neurone in Aplysia. Comp. Biochem. Physiol. 54C: 109-113.

Chang, J. J., and A. Gelperin (1980) Rapid taste-aversion learning by an isolated molluscan central nervous system. Proc. Natl. Acad. Sci. U. S. A. 77: 6204-6206.

Copeland, J., and A. Gelperin (1983) Feeding and a serotonergic interneuron activate an identified autoactive salivary neuron in Limax maximus. Comp. Biochem. Physiol., in press.

Cottrell, G. A., M. S. Berry, and J. B. Macon (1974) Synapses of a giant serotonin neurone and a giant dopamine neurone: Studies using antagonists. Neuropharmacology 13: 431-439.

Cottrell, G. A., and N. N. Osborne (1970) Serotonin: Subcellular localization in an identified serotonin-containing neuron. Nature 225: 470-472.

Creese, I., D. R. Sibley, M. W. Hamblin, and S. E. Leff (1983) The classification of dopamine receptors: Relationship to radioligand binding. Annu. Rev. Neurosci. 6: 43-71.

Culligan, N., and A. Gelperin (1983) One trial associative learning by an isolated molluscan CNS: Use of different chemoreceptors for training and testing. Brain Res. 266: 319-327.

de la Torre, J. C. (1980) An improved approach to histofluorescence using the SPG method for tissue monoamines. J. Neurosci. Methods 3: 1-5.

Euvrard, C., L. Ferland, T. DiPaolo, M. Beaulieu, F. Labrie, C. Oberlander, J. P. Raynaud, and J. R. Boissicr (1980) Activity of two new potent dopaminergic agonists at the striatal and anterior pituitary levels. Neuropharmacology 19: 379-386.

Gelperin, A. (1975) Rapid food-aversion learning by a terrestrial mollusk. Science 189: 567-570.

Gelperin, A. (1981) Synaptic modulation by identified serotonin neurons. In Serotonin Neurotransmission and Behavior, B. L. Jacobs and A. Gelperin, eds., pp. 288-304, MIT Press, Cambridge, MA.

Gelperin, A. (1983) Neuroethological studies of associative 
learning in feeding control systems. In Behavioral Physiology and Neuroethology: Roots and Growing Points, F. Huber and H. Markl, eds., Springer-Verlag, New York, in press.

Gelperin, A., J. J. Chang, and S. C. Reingold (1978) Feeding motor program in Limax. I. Neuromuscular correlates and control by chemosensory input. J. Neurobiol. 9: 285-300.

Gillette, R., and W. J. Davis (1977) The role of the metacerebral giant neuron in the feeding behavior of Pleurobranchaea. J. Comp. Physiol. 116: 129-159.

Gospe, S. M., Jr., and W. A. Wilson, Jr. (1980) Dopamine inhibits burst-firing of neurosecretory cell R15 in Aplysia californica: Establishment of a dose-response relationship. J. Pharmacol. Exp. Ther. 214: 112-118.

Granzow, B., and S. B. Kater (1977) Identified higher-order neurons controlling the feeding motor program of Helisoma. Neuroscience 2: 1049-1063.

Hildebrand, J. G., D. L. Barker, E. Herbert, and E. A. Kravitz (1971) Screening for neurotransmitters: A rapid radiochemical procedure. J. Neurobiol. 2: 231-246.

Iversen, L. I. (1975) Dopamine receptors in the brain. Science 188: 1084-1089.

Jacobs, B. L., and A. Gelperin (1981) Serotonin Neurotransmission and Behavior, MIT Press, Cambridge, MA.

Kandel, E. R., and J. H. Schwartz (1982) Molecular biology of learning: Modulation of transmitter release. Science 218: 433-443.

Kandel, E. R., and W. A. Spencer (1961) Electrophysiology of hippocampal neurons. I. After potentials and repetitive firing. J. Neurophysiol. 21: 213-259.

Kebabian, J. W., and D. B. Calne (1979) Multiple receptors for dopamine. Nature 277: 93-96.

Kupfermann, 1., and K. R. Weiss (1981) The role of serotonin in arousal of feeding behaviors of Aplysia. In Serotonin Neurotransmission and Behavior, B. L. Jacobs and A. Gelperin, eds., pp. 255-287, MIT Press, Cambridge, MA.

Kushner, P. D., and E. A. Maynard (1977) Localization of monoamine fluorescence in the stomatogastric nervous system of lobsters. Brain Res. 129: 13-28.

Livingston, M. S., R. M. Harris-Warrick, and E. A. Kravitz (1980) Serotonin and octopamine produce opposite postures in lobsters. Science 208: 76-79.

McCrohan, C. R., and P. R. Benjamin (1980) Synaptic relationships of the cerebral giant cells with motoneurons in the feeding system of Lymnaea stagnalis. .J. Fxp. Biol. 85: 169186.

Mefford, I. N. (1981) Application of high performance liquid chromatography with electrochemical detection to neurochemical analysis: Measurement of catecholamines, serotonin and metabolites in rat brain. J. Neurosci. Methods 3: 207-224.

Moore, R. Y. (1981) Fluorescence histochemical methods. In
Neuroanatomical Tract-Tracing Methods, L. Heimer and M. J. RoBards, eds., pp. 441-482, Plenum Press, New York.

Osborne, N. N. and G. A. Cottrell (1971) Distribution of biogenic amines in the slug Limax maximus. Z. Zellforsch. 112 : 15-30.

Prior, D., and A. Gelperin (1977) Autoactive molluscan neuron: Reflex function and synaptic modulation during feeding in the terrestrial slug Limax maximus. J. Comp. Physiol. 114: 217-232.

Prior, D. J., and D. S. Grega (1982) Effects of temperature on the endogenous activity and synaptic interactions of the salivary burster neurones in the terrestrial slug Limax maximus. J. Exp. Biol. 98: 415-428.

Reingold, S. C., and A. Gelperin (1980) Feeding motor program in Limax. II. Modulation by sensory inputs in intact animals and isolated central nervous system. J. Exp. Biol. 85: 1-19.

Sahley, C. L., A. Gelperin, and J. Rudy (1981) One-trial associative learning modifies food odor preferences of a terrestrial mollusc. Proc. Natl. Acad. Sci. U. S. A. 78: 640-642.

Sahley, C., J. W. Rudy, and A. Gelperin (1983) Associative learning in a mollusc: A comparative analysis. In Primary Neural Substrates of Learning and Behavioral Change, D. Alkon and J. Farley, eds., Cambridge University Press, New York, in press.

Seeman, P. (1980) Brain dopamine receptors. Pharmacol. Rev. 32: 229-313.

Siegelbaum, S. A., J. S. Camardo, and E. R. Kandel (1982) Serotonin and cyclic AMP close single $\mathrm{K}^{+}$channels in Aplysia sensory neurones. Nature 299: 413417.

Stoof, J. C. and J. W. Kebabian (1981) Opposing roles for D1 and D2 dopamine receptors in efflux of cyclic AMP from rat neostriatum. Nature 294: 366-368.

Trimble, D. L., and D. L. Barker (1982) Dopamine neurons in the buccal ganglia of Helisoma trivolvis. Soc. Neurosci. Abstr. 8: 162.

Walker, R. J., G. N. Woodruff, B. Glaizner, C. B. Sedden, and G. A. Kerkut (1968) 'Ihe pharmacology of Helix dopamine receptor of specific neurons in the snail, Helix aspersa. Comp. Biochem. Physiol. 24: 455-469.

Wieland, S. J., and A. Gelperin (1982) Monoamines and the control of the feeding system in Limax maximus. Soc. Neurosci. Abstr. 8: 823.

Willard, A. L. (1981) Effects of serotonin on the generation of the motor program for swimming by the medicinal leech. J. Neurosci. 1: 936-944.

Wilson, W. A., and H. Wachtel (1978) Prolonged inhibition in burst firing neurons: Synaptic inactivation of the slow regenerative inward current. Science 202: 772-775.

Wong, R. K. S., and D. A. Prince (1978) Participation of calcium spikes during intrinsic burst firing in hippocampal neurons. Brain Res. 159: 385-390. 